\title{
Stage III Hypopharyngeal Squamous Cell Carcinoma AJCC v7
}

National Cancer Institute

\section{Source}

National Cancer Institute. Stage III Hypopharyngeal Squamous Cell Carcinoma A/CC v7. NCl Thesaurus. Code C8234.

Stage III includes: (T3, N0, M0); (T1, N1, M0); (T2, N1, M0); (T3, N1, M0). T3: Tumor measuring more than $4 \mathrm{~cm}$ in greatest dimension or with fixation of hemilarynx or extension to esophagus. T1: T umor limited to one subsite of hypopharynx and/or $2 \mathrm{~cm}$ or less in greatest dimension. T2: Tumor invades more than one subsite of the hypopharynx or an adjacent site, or measures more than $2 \mathrm{~cm}$ but not more than $4 \mathrm{~cm}$ in greatest diameter without fixation of hemilarynx. N0: No regional lymph node metastasis. N1: Metastasis in a single ipsilateral lymph node, $3 \mathrm{~cm}$ or less in greatest dimension. M0: No distant metastasis. (AJCC 7th ed.) 